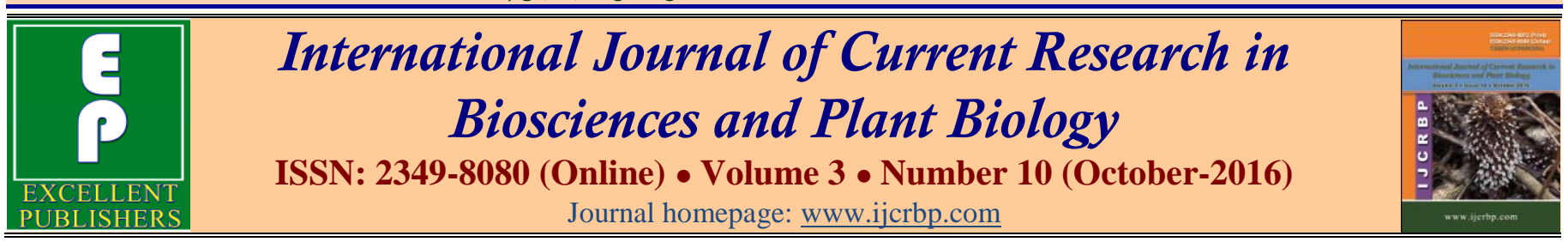

\title{
Phytochemical Screening, Larvicidal and Pupicidal Activity of Murraya paniculata (L.) Jack (Rutaceae) Leaf Extracts against Three Important Vector Mosquitoes (Diptera: Culicidae)
}

\author{
G. Ramar'1 and A. Jeyasankar ${ }^{2 *}$
}

${ }^{1} P G$ \& Research Department of Zoology, Arignar Anna Government Arts College, Musiri-621 211, Tamil Nadu, India ${ }^{2}$ Entomology Unit, PG \& Research Department of Zoology, Government Arts College (Autonomous), Coimbatore-641 o18, Tamil Nadu, India

*Corresponding author.

\begin{abstract}
A b stract
Phytochemical represents a rich resource for the discovery of novel pesticides that are effective, cheap and environmentally safe. The main target mosquito vectors, Aedes aegypti, Anopheles stephensi and Culex quinquefasciatus cause serious human diseases. The petroleum ether, chloroform and ethyl acetate extracts of Murraya paniculata were studied for larvicidal and pupicidal activity against the mosquitoes, Ae. aegypti, An. stephensi and $C x$. quinquefasciatus. The results of the present study showed that the chloroform extracts of $M$. paniculata leaves against the larvae and pupae of the mosquito, An. stephensi with high mortality and $\mathrm{LC}_{50}$ values of 44.72 and $48.01 \mathrm{ppm}$ respectively. The results suggest that the chloroform leaf extract of $M$. paniculata have the potential to be used as good larvicidal and pupicidal agent.
\end{abstract}

\section{Article Info}

Accepted: 28 September 2016

Available Online: 06 October 2016

\author{
Keywords \\ Larvicidal activity \\ Leaf extract \\ Murraya paniculata \\ Phytochemical analysis \\ Pupicidal activity \\ Vector mosquitoes
}

\section{Introduction}

Three mosquito species of the genera Anopheles, Culex and Aedes are vectors responsible for the pathogens of various diseases like malaria, filariasis, Japanese encephalitis, dengue fever and yellow fever. Most parasitic disease is the tropical, indentifying globalization and climatic changes are increasing the danger of contracting arthropod borne diseases (Ansari, 2000; Tawatsin et al., 2001). Most popular centuries, the vector-borne diseases are imposing a serious public health problem in human's deaths worldwide. Besides their negative public health impact, these diseases are also posing a serious obstacle to socio-economic development in countries wherever they are endemic in nature (Karunamoorthi and Sabesan, 2010). Ae. aegypti is vector of Dengue and Chikungunya.
Approximately 3.5 billion people live in dengue endemic countries which are located in the tropical and subtropical regions of the world (WHO, 2011a). Lymphatic filariasis, commonly known as elephantiasis is so far a neglected tropical disease. The infection occurs when filarial parasites are transmitted to humankind through $C x$. quinquefasciatus (WHO, 2011b). Anopheline adults reset with their abdomens positioned at a discrete angle to the surface, whereas other species keep their bodies parallel to the surface, which makes them easy to identify when sitting on the skin (Rutletdge et al., 2005). The larvae lie horizontally at the surface of the water where they filter feed on organic material. They do not possess the breathing siphon present on other mosquito genera. They obtain oxygen through palmate hairs along the abdomen. The food sources include a variety of plant and animal matter 
suspended at the surface of the water and small enough to eat (O'Malley, 1992). According to WHO data, Plasmodium falciparum malaria is exclusively trans-mitted by Anopheles arabiensis Patton and Anopheles gambiae Gilesin Djibouti (WHO, 2013). Although the Horn of Africa is known to be highly susceptible to mosquito-borne infectious diseases, Dji-bouti was formerly thought to be a meso- to hypo-endemic country with unstable malaria transmission (Carteron et al., 1978).

Medicinal plant is Murraya paniculata (L.) Jack, otherwise known as Murraya exotica L., belonging to the Rutaceae family. The folk medicinal practitioners of Jessore district in Bangladesh advise boiling the leaves of the plant in water and then gargling with the water (to which a little table salt has been added) three to four times daily for three days (Islam et al., 2011). Stems of the plant are also used for toothache and oral care in India (Kumar, 2014), where traditional practitioners advise brushing teeth with stems to get relief from toothache and for maintaining healthy gums and teeth. Therefore the present study was carried out to determine the larvicidal and pupicidal activity of $M$. paniculata leaf extracts against important vectors An. stephensi.

\section{Materials and methods}

\section{Plant material}

The leaves of M. paniculata were collected from Arignar Anna Government Arts College, Musiri, Trichy District, Tamil Nadu, India during the July 2014. The collected plant specimen was identified by Dr. S. John Britto, Director, The Rapinat Herbarium and Centre for Molecular Sytematics, St' Joseph's College, Tiruchirapalli, Tamil Nadu, India and The Voucher specimen (IPH 39) was deposited in Entomology lab, Arignar Anna Government Arts College, Musiri, Tamil Nadu, India.

\section{Extraction method}

The dried leaves $(100 \mathrm{~g})$ were powdered mechanically using commercial electrical stainless steel blender and extracted sequentially with petroleum ether, chloroform, and ethyl acetate $(500 \mathrm{ml}$, Ranchem), in a Soxhlet apparatus separately until exhaustion. The extract was concentrated under reduced pressure of $22-26 \mathrm{~mm}$ hg at $45^{\circ} \mathrm{C}$ by 'Rotavapour' and the residue obtained was stored at $4^{\circ} \mathrm{C}$ in an amber vial. Then the vials were named and covered with silver foil. Until use those vials were kept in cool and dark place at $4^{\circ} \mathrm{C}$.

\section{Phytochemical screening}

The phytochemical screening of chloroform extract of $M$. paniculata leaves was carried out with the following standard procedures, since it showed higher larvicidal and pupicidal activity.

Test for alkaloids (Wagner's reagent): A fraction of extract was treated with 3-5drops of Wagner's reagent [ $1.27 \mathrm{~g}$ of iodine and $2 \mathrm{~g}$ of potassium iodide in $100 \mathrm{ml}$ of water] and observed for the formation of reddish brown precipitate (or colouration).

Anthraquinones: About $0.5 \mathrm{~g}$ of each extract was boiled with $10 \% \mathrm{HCl}$ for few minutes in water bath, filtered and allowed to cool. Equal volume of $\mathrm{CHCl}$ was added to the filtrates. Few drops of $10 \%$ ammonia was added to the mixtures and heated. Formation of rose-pink color indicated the presence of anthraquinones.

Catechin: Few mg of the substrate in alcohol is treated with a few drops of Ehrlish reagent and a few drops of concentrated $\mathrm{HCl}$. The pink colour developed indicates the presence of catechin.

Coumarins: 10mg of the extract is dissolved in methanol and alcoholic $\mathrm{KOH}$ was added. The appearance of yellow colour which decolorizes while adding conc. HCL shows the presence of coumarin.

Flavonoids: $10 \mathrm{mg}$ of the extract was dissolved in methanol. Magnesium turnings were added into this followed by conc. HCL. A magneta colour shows the presence of flavonoids.

Test for phenols (ferric chloride test): A fraction of the extracts was treated with aqueous $5 \%$ ferric chloride and observed for formation of deep blue or black colour.

Test for quinines: A small amount of extract was treated with concentrated HCL and observed for the formation of yellow precipitate (or colouration).

Test for saponins (foam test): To $2 \mathrm{mls}$ of extract was added $6 \mathrm{ml}$ of water in a test tube. The mixture was shaken vigorously and observed for the formation of persistent foam that confirms the presence of saponins.

Steroids: To test the presence of steroid phytochemicals, $1 \mathrm{ml}$ of extract dissolved in $10 \mathrm{ml}$ chloroform and equal volume of concentrated sulphuric acid $\left(\mathrm{H}_{2} \mathrm{SO}_{4}\right)$ added by sides of test tube. The upper layer turns red and sulphuric 
acid layer shown yellow with green fluorescence. This indicated the presence of steroids.

Test for tannins (Braymer's test): $2 \mathrm{ml}$ of extract was treated with $10 \%$ alcoholic ferric chloride solution and observed for formation of blue or greenish colour solution.

Test for terpenoids (Salkowki's test): $1 \mathrm{ml}$ of chloroform was added to $2 \mathrm{ml}$ of each extract followed by a few drops of concentrated sulphuric acid. A reddish brown precipitate produced immediately indicated the presence of terpenoids.

\section{Vector rearing}

The larvae of the mosquitoes, Ae. aegypti, An. stephensi and $C x$. quinquefasciatus were collected from National centre for disease control, Government of India ministry of health and family welfare, Southern India branch, field station, Mettupalayam. The larvae were kept in the plastic buckets half filled with tap water and fed with dog biscuit once a day initially and twice during the later stages of development. Water in rearing container was refreshed every day by removing a little quantity of water from the rearing buckets and replacing with fresh water. This was aimed at preventing scum from forming on the water surface.

\section{Larvicidal bioassay}

The larvicidal activity of selected plants extracts were evaluated as per the protocol previously described WHO (2005), Based on the wide range and narrow range tests, all extracts tested ranging 30-200ppm were prepared and they were tested against the freshly moulted (0-6 hrs) third instar larvae of selected mosquito species. The plants oils were dissolved in 2 drop twin-20 and then diluted in $100 \mathrm{ml}$ of dechlorinated tap water to obtain each of the desired concentrations. The control was prepared using 2 drops of tween-20 in $100 \mathrm{ml}$ of dechlorinated water. The larvae of test species (10) were introduced in $250-\mathrm{ml}$ plastic cups containing $100 \mathrm{ml}$ of aqueous medium $(100 \mathrm{ml}$ of dechlorinated +2 drops tween-20) and the required amount of chemical compositions was added. The larval mortality was observed and recorded after $24 \mathrm{hrs}$ of post treatment. For each experiment, five replicates were maintained at a time. The $\mathrm{LC}_{50}$ value was calculated by using Probit analysis (Finney, 1971). The average mortality data were subjected to Probit analysis for calculating $\mathrm{LC}_{50}, \mathrm{LC}_{90}$ and other statistics chi-square values were calculated by using software, Statistical Package of Social Sciences (SPSS) version 16.0 for Windows and the significance level was set at $p \leq 0.05$.

\section{Pupicidal bioassay}

The pupicidal activity of plant crude extract will be assessed by using the standard method as prescribed by WHO (2005). Similar test concentrations as stated in the previous experiments were prepared and tested against the pupae of Ae. aegypti, An. stephensi and $C x$. quinquefasciatus. Tween-20 (emulsifier) in water was treated as control. The pupae of these mosquito species (10 pupae) were introduced in 250-ml plastic cups containing $100 \mathrm{ml}$ of aqueous medium $(100 \mathrm{ml}$ of dechlorinated water +2 drops of tween-20) and the required amount of plant extract was added. The pupal mortality will be observed and recorded after $24 \mathrm{hrs}$ of post treatment. For each experiment, five replicates were maintained at a time. The percentage of mortality was calculated by using Abbott's formula (Abbott, 1925).

\section{Results and discussion}

The present study was carried out on the plant samples revealed the presence of medicinally important bioactive compounds. Since the activity studied in the present study showed good results in the chloroform leaf extracts of $M$. paniculata, the phytochemical screening of chloroform extracts was carried out. The plant $M$. paniculata showed the presence of alkaloids, coumarin, quinines, steroids, tannins, terpenoids from chloroform extract (Table 1).

Table 1. Preliminary phytochemical analysis of leaf crude extracts of M. paniculata.

\begin{tabular}{ll}
\hline Phytochemical compounds & Leaf crude extract \\
\hline Alkaloids & + \\
Anthraquinones & - \\
Catechin & - \\
Coumarin & + \\
Flavonoids & - \\
Phenols & - \\
Quinines & + \\
Saponins & - \\
Steroids & + \\
Tannins & + \\
Terpenoids & + \\
\hline + Presence of compound; - Absence of compound.
\end{tabular}


Table 2. Larvicidal activity of $M$. paniculata leaf extracts against three important vector mosquitoes.

\begin{tabular}{|c|c|c|c|c|c|c|c|c|c|c|c|c|c|}
\hline \multirow[t]{2}{*}{ Leaf extract used } & \multicolumn{5}{|c|}{$\begin{array}{l}\text { Larval mortality }(\%) \text { in different } \\
\text { concentration of extracts (ppm) }\end{array}$} & \multirow{2}{*}{$\begin{array}{l}\mathbf{L C}_{50} \\
(\mathbf{p p m})\end{array}$} & \multicolumn{2}{|c|}{$\begin{array}{l}95 \% \text { of Confidence } \\
\text { limit (ppm) }\end{array}$} & \multirow{2}{*}{$\begin{array}{l}\mathbf{L C}_{90} \\
(\mathbf{p p m})\end{array}$} & \multicolumn{2}{|c|}{$\begin{array}{l}\text { 95\% of Confidence limit } \\
\text { (ppm) }\end{array}$} & \multirow{2}{*}{$\begin{array}{l}\chi^{2} \\
(\mathrm{df}=4)\end{array}$} & \multirow{2}{*}{$\begin{array}{l}\text { Chi- } \\
\text { square } \\
\text { test }\end{array}$} \\
\hline & 50 & 100 & 150 & 200 & 250 & & LCL & UCL & & LCL & UCL & & \\
\hline \multicolumn{14}{|c|}{ Larvicidal activity of $M$. paniculata against Ae. aegypti } \\
\hline Pet-Eth LE & $\begin{array}{l}42.2 \\
\pm 1.6\end{array}$ & $\begin{array}{l}53.6 \\
\pm 2.0\end{array}$ & $\begin{array}{l}66.2 \\
\pm 2.4\end{array}$ & $\begin{array}{r}75.8 \\
\pm 2.6\end{array}$ & $\begin{array}{l}85.6 \\
\pm 2.9\end{array}$ & 83.58 & 53.07 & 104.79 & 289.26 & 253.20 & 349.43 & 3.311 & 0.082 \\
\hline Chloroform LE & $\begin{array}{l}46.8 \\
\pm 1.6\end{array}$ & $\begin{array}{l}63.2 \\
\pm 3.4\end{array}$ & $\begin{array}{l}73.6 \\
\pm 3.8\end{array}$ & $\begin{array}{l}82.2 \\
\pm 3.2\end{array}$ & $\begin{array}{l}90.8 \\
\pm 1.9\end{array}$ & 57.58 & 22.73 & 80.64 & 246.20 & 217.83 & 291.48 & 2.383 & 0.307 \\
\hline Eth-Acet LE & $\begin{array}{l}35.4 \\
\pm 2.3\end{array}$ & $\begin{array}{l}45.6 \\
\pm 3.3\end{array}$ & $\begin{array}{l}56.8 \\
\pm 2.1\end{array}$ & $\begin{array}{l}69.8 \\
\pm 2.5\end{array}$ & $\begin{array}{l}82.2 \\
\pm 2.9\end{array}$ & 115.21 & 92.69 & 133.40 & 315.49 & 276.60 & 379.44 & 5.426 & 0.489 \\
\hline \multicolumn{14}{|c|}{ Larvicidal activity of $M$. paniculata against $A n$. stephensi } \\
\hline Pet-Eth LE & $\begin{array}{l}46.4 \\
\pm 2.5\end{array}$ & $\begin{array}{l}66.8 \\
\pm 3.5\end{array}$ & $\begin{array}{l}76.2 \\
\pm 3.6\end{array}$ & $\begin{array}{l}83.8 \\
\pm 2.9\end{array}$ & $\begin{array}{l}91.6 \\
\pm 3.2\end{array}$ & 52.57 & 17.62 & 75.69 & 234.27 & 208.04 & 275.27 & 1.278 & 1.088 \\
\hline Chloroform LE & $\begin{array}{l}52.8 \\
\pm 2.2\end{array}$ & $\begin{array}{l}65.8 \\
\pm 1.3\end{array}$ & $\begin{array}{l}84.4 \\
\pm 3.2\end{array}$ & $\begin{array}{l}90.2 \\
\pm 1.0\end{array}$ & $\begin{array}{l}96.4 \\
\pm 1.3\end{array}$ & 44.72 & 14.61 & 65.32 & 192.30 & 172.98 & 219.98 & 5.498 & 0.870 \\
\hline Eth-Acet LE & $\begin{array}{l}45.4 \\
\pm 1.1\end{array}$ & $\begin{array}{l}53.6 \\
\pm 2.7\end{array}$ & $\begin{array}{l}66.2 \\
\pm 3.3\end{array}$ & $\begin{array}{l}75.2 \\
\pm 2.7\end{array}$ & $\begin{array}{l}84.8 \\
\pm 3.8\end{array}$ & 76.74 & 40.60 & 100.45 & 301.00 & 260.30 & 372.41 & 3.877 & 0.294 \\
\hline \multicolumn{14}{|c|}{ Larvicidal activity of $M$. paniculata against $C x$. quinquefasciatus } \\
\hline Pet-Eth LE & $\begin{array}{l}44.8 \\
\pm 1.4\end{array}$ & $\begin{array}{l}62.6 \\
\pm 2.0\end{array}$ & $\begin{array}{l}72.8 \\
\pm 1.9\end{array}$ & $\begin{array}{l}83.4 \\
\pm 3.6\end{array}$ & $\begin{array}{l}90.4 \\
\pm 2.5\end{array}$ & 62.96 & 31.37 & 84.48 & 243.98 & 216.86 & 286.37 & 2.059 & 0.327 \\
\hline Chloroform LE & $\begin{array}{l}49.4 \\
\pm 3.3\end{array}$ & $\begin{array}{l}65.9 \\
\pm 2.9\end{array}$ & $\begin{array}{l}76.4 \\
\pm 2.4\end{array}$ & $\begin{array}{l}85.4 \\
\pm 2.0\end{array}$ & $\begin{array}{l}94.4 \\
\pm 1.8\end{array}$ & 52.06 & 19.63 & 73.92 & 221.21 & 197.56 & 257.11 & 4.511 & 0.454 \\
\hline Eth-Acet LE & $\begin{array}{l}44.4 \\
\pm 3.4\end{array}$ & $\begin{array}{l}57.2 \\
\pm 1.5\end{array}$ & $\begin{array}{l}66.4 \\
\pm 2.4\end{array}$ & $\begin{array}{r}75.2 \\
\pm 3.2\end{array}$ & $\begin{array}{l}86.2 \\
\pm 3.1\end{array}$ & 74.05 & 38.10 & 97.63 & 292.85 & 254.21 & 359.72 & 3.216 & 0.397 \\
\hline
\end{tabular}

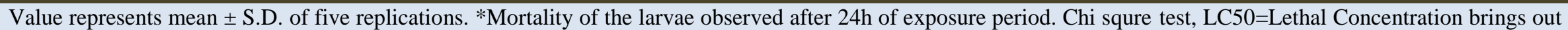

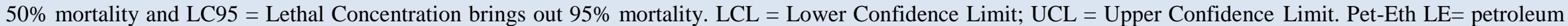
ether leaf extract; Chloroform LE= chloroform leaf extract; Eth-Acet LE= ethyl acetate leaf extract. 
As shown in Table 2 above, the efficacy of $M$. paniculata against the $4^{\text {th }}$ instar larvae of Ae. aegypti, An. stephensi and $C x$. quinquefasciatus showed moderate to good larvicidal activity. The chloroform extract of M. paniculata showed highest larvicidal activity against Ae. aegypti, An. stephensi and $C x$. quinquefasciatus with the $\mathrm{LC}_{50}$ values of $57.58,44.72$ and $52.06 \mathrm{ppm}$ respectively with the respective $\mathrm{LC}_{90}$ values of $246.20,192.30$ and $221.21 \mathrm{ppm}$ followed by petroleum ether of larvicidal activity against Ae. aegypti, An. stephensi and Cx. quinquefasciatus $\left(\mathrm{LC}_{50}\right.$ values of $83.58,52.57$ and $62.96 \mathrm{ppm}$ respectively; $\mathrm{LC}_{90}$ values of 289.26, 234.27 and 243.98ppm respectively). Ethyl acetate extract of $M$. paniculata showed least larvicidal activity among the extracts used (Table 2). The pupicidal activity of the leaf extracts of $M$. paniculata is provided in Tables 3, 4 and 5. The chloroform extract of $M$. paniculata showed highest pupicidal activity against Ae. aegypti, An. stephensi and Cx. quinquefasciatus $\left(\mathrm{LC}_{50}\right.$ values $=53.06,48.01$ and 53.34 respectively; and $\mathrm{LC}_{90}$ values $234.85,187.32$ and $210.77 \mathrm{ppm}$ respectively), followed by petroleum ether leaf extract (Table 3). Ethyl acetate leaf extract of $M$. paniculata showed a pupicidal activity in terms of $\mathrm{LC}_{50}$ values, 149.50, 83.67 and 81.44 ppm respectively against Ae. aegypti, An. stephensi and $C x$. quinquefasciatus (Table 5). The Chi-square values were significant at $p<0.05$ level.

Table 3. Pupicidal activity of $M$. paniculata leaf extracts against Ae. aegypti.

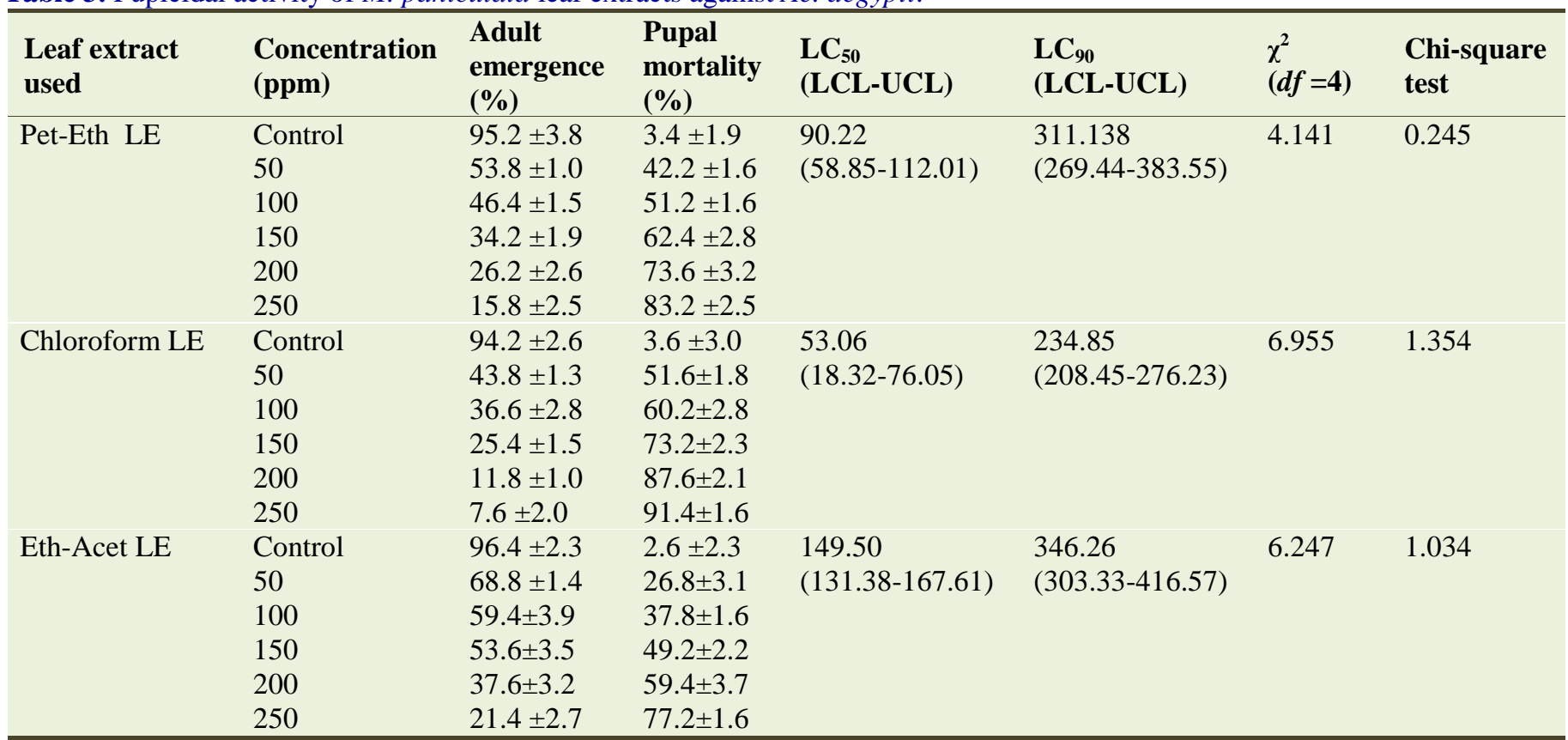

Values represent mean \pm S.D. of five replications. *Mortality of the pupae observed after $24 \mathrm{hrs}$ of exposure period. Chi square test, LC50=Lethal Concentration brings out 50\% mortality and LC95 = Lethal Concentration brings out 95\% mortality. LCL = Lower Confidence Limit; UCL = Upper Confidence Limit. Pet-Eth LE= petroleum ether leaf extract; Chloroform LE= chloroform leaf extract; Eth-Acet LE= ethyl acetate leaf extract.

The results of present study are comparable with similar reports of earlier workers. The toxicity to the third instar larvae of Ae. aegypti, Cx. quinquefasciatus and An. stephensi by the ethyl acetate leaf extract of Breyenia vitisidaea showed the $\mathrm{LC}_{50}$ value of $98.2,107.79$ and 115.8ppm respectively (Jeyasankar and Ramar, 2014a). The investigation by Ramar et al. (2014) was designed to determine the larvicidal activity of silver nanoparticles synthesized from aqueous leaf extract of Cleistanthus collinus against the larvae of Ae. aegypti, and the synthesized nanoparticles exhibited significant larvicidal activity. This shows that the nanoparticles synthesized from plant extracts also possess mosquito larvicidal activity. The toxicity to the third instar larvae of $A e$. aegypti, Cx. quinquefaciatus and An. stephensi by the ethyl acetate leaf extract of Andrographis paniculata showed the least $\mathrm{LC}_{50}$ value of 20.85 (Jeyasankar and Ramar, 2015a). The toxicity study of Tragia involucrata leaf extract showed good larvicidal activity against the dengue vector mosquito Ae. aegypti (Jeyasankar and Ramar, 2014b). The petroleum ether extract of Andrographis paniculata against mosquito vectors exhibited more than $85 \%$ pupal mortality and $100 \%$ ovicidal activity at 250ppm (Jeyasankar and Ramar, 2015b). The methanol extracts of Solanum trilobatum was found to be susceptible to the larvae of $A e$. aegypti, Cx. quinquefaciatus and An. stephensi at 250ppm 
with the $\mathrm{LC}_{50}$ values of $125.43,127.77$ and $116.64 \mathrm{ppm}$ respectively (Premalatha et al., 2013). The results of the present study showed that the chloroform extracts of $M$. paniculata against larvicidal and pupicidal activity with high mortality with $\mathrm{LC}_{50}$ value of 44.72 and $48.01 \mathrm{ppm}$ respectively. The results suggest that the chloroform leaf extract of $M$. paniculata have the potential to be used as good larvicidal and pupicidal agent.

Table 4. Pupicidal activity of M. paniculata leaf extracts against An. stephensi.

\begin{tabular}{|c|c|c|c|c|c|c|c|}
\hline $\begin{array}{l}\text { Leaf extract } \\
\text { used }\end{array}$ & $\begin{array}{l}\text { Concentration } \\
\text { (ppm) }\end{array}$ & $\begin{array}{l}\text { Adult } \\
\text { emergence } \\
(\%)\end{array}$ & $\begin{array}{l}\text { Pupal } \\
\text { mortality } \\
(\%)\end{array}$ & $\begin{array}{l}\mathbf{L C}_{50} \\
\text { (LCL-UCL) }\end{array}$ & $\begin{array}{l}\mathbf{L C}_{90} \\
\text { (LCL-UCL) }\end{array}$ & $\begin{array}{l}\chi^{2} \\
(d f=4)\end{array}$ & $\begin{array}{l}\text { Chi-square } \\
\text { test }\end{array}$ \\
\hline \multirow[t]{4}{*}{ Pet-Eth LE } & Control & $92.4 \pm 3.9$ & $5.2 \pm 1.3$ & \multirow{4}{*}{$\begin{array}{l}60.98 \\
(29.37-82.52)\end{array}$} & \multirow{4}{*}{$\begin{array}{l}239.39 \\
(213.12-280.09)\end{array}$} & \multirow[t]{4}{*}{1.039} & \multirow[t]{4}{*}{0.790} \\
\hline & 100 & $35.4 \pm 1.5$ & $62.4 \pm 2.5$ & & & & \\
\hline & 150 & $23.4 \pm 3.2$ & $76.4 \pm 1.5$ & & & & \\
\hline & 200 & $13.8 \pm 1.6$ & $83.7 \pm 3.7$ & & & & \\
\hline \multirow{5}{*}{ Chloroform LE } & 50 & $50.6 \pm 2.8$ & $47.4 \pm 2.8$ & \multirow{5}{*}{$\begin{array}{l}48.01 \\
(20.41-67.26)\end{array}$} & \multirow{5}{*}{$\begin{array}{l}187.32 \\
(169.11-212.96)\end{array}$} & \multirow{5}{*}{4.006} & \multirow{5}{*}{2.999} \\
\hline & 100 & $23.2 \pm 2.5$ & $74.4 \pm 2.3$ & & & & \\
\hline & 150 & $15.8 \pm 2.7$ & $81.4 \pm 2.9$ & & & & \\
\hline & 200 & $6.8 \pm 2.1$ & $89.8 \pm 3.9$ & & & & \\
\hline & 250 & $2.2 \pm 1.3$ & $97.6 \pm 1.6$ & & & & \\
\hline \multirow{2}{*}{ Eth-Acet LE } & 200 & $21.8 \pm 3.2$ & $77.6 \pm 3.2$ & \multirow{2}{*}{$\begin{array}{l}83.67 \\
(53.74-104.60)\end{array}$} & \multirow{2}{*}{$\begin{array}{l}286.52 \\
(251.21-345.01)\end{array}$} & \multirow{2}{*}{5.557} & \multirow{2}{*}{0.593} \\
\hline & 250 & $12.4 \pm 1.6$ & $86.2 \pm 2.9$ & & & & \\
\hline
\end{tabular}

Values represent mean \pm S.D. of five replications. *Mortality of the pupae observed after 24 hrs of exposure period. Chi square test, LC50=Lethal Concentration brings out 50\% mortality and LC95 = Lethal Concentration brings out 95\% mortality. LCL = Lower Confidence Limit; UCL = Upper Confidence Limit. Pet-Eth LE= petroleum ether leaf extract; Chloroform LE= chloroform leaf extract; Eth-Acet LE= ethyl acetate leaf extract.

Table 5. Pupicidal activity of M. paniculata leaf extracts against $C x$. quinquefasciatus.

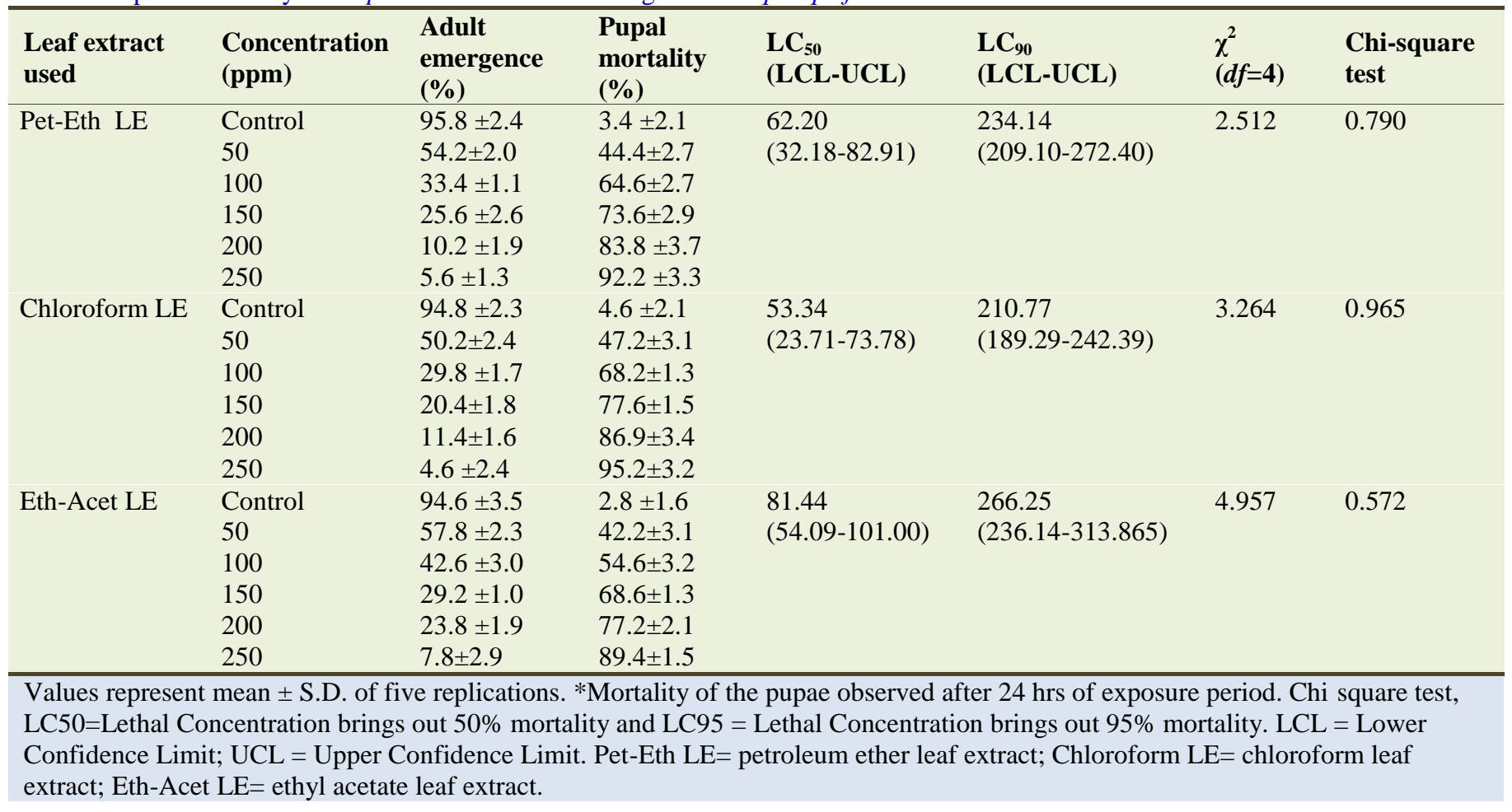




\section{Conclusion}

Phytochemicals are relatively safe, inexpensive and readily available in plants elsewhere. Several plants are used in traditional medicines for the mosquito larvicidal activities in many parts of the world. The results suggest that the chloroform leaf extract of $M$. paniculata have the potential to be used as good larvicidal and pupicidal agents.

\section{Conflict of interest statement}

Authors declare that they have no conflict of interest.

\section{References}

Abbott, W.S., 1925. A method of computing the effectiveness of an insecticide. J. Econ. Entomol. 18, 265-267.

Ansari, M.A., 2000. Larvicidal and mosquito repellent action of peppermint (Mentha piperita) oil. Bioresour. Technol. 71(3), 267-271.

Carteron, B., Morvan, D., Rodhain, F., 1978. Le problème de l'endémie palustre dansla République de Djibouti. Med. Trop. (Mars), 38, 299-304.

Finney, D. J., 1971. Probit Analysis. $3^{\text {rd }}$ Edn. Cambridge Univ. Press, London.

Islam, F., Jahan, F.I., Seraj, S., Malek, I., Sadat, A.F., Bhuiyan, M.A., et al., 2011. Variations in disease and medicinal plant selection among folk medicinal practitioners: A case study in Jessore district, Bangladesh. Amer.-Euras. J. Sustain. Agric. 5(2), 282-291.

Jeyasankar, A., Ramar, G., 2015a. Larvicidal activity of Andrographis paniculata (Acanthaceae) against important human vector mosquitoes (Diptera: Culicidae). Int. J. Adv. Res. Biol. Sci. 2(10), 156-160.

Jeyasankar, A., Ramar, G., 2015b. Ovicidal and pupicidal activity of Andrographis paniculata (Acanthaceae) against vector mosquitoes (Diptera: Culicidae). Int. J. Curr. Res. Med. Sci. 1(3), 53-61.

Jeyasankar, A., Ramar, G., 2014a. Larvicidal properties of Breyenia vitis-idaea (Burm.F) Fischer (Euphorbiaceae) against important vector mosquitoes (Diptera: Culicidae). J. Vector Borne Dis. 51, 153-164.
Jeyasankar, A., Ramar, G., 2014b. Larvicidal activity of Tragia involucrata Linn. (Euphorbiacea) leaf extracts against against chikungunya vector, Ae. aegypti (Linn.) (Diptera: Culicidae). J. Coastal Life Med. 2(7), 555-558.

Karunamoorthi, K., Sabesan, S., 2010. Laboratory evaluation of Dimethyl phthalate treated wristbands against three predominant mosquito (Diptera: Culicidae) vectors of disease. Eur. Rev. Med. Pharmacol. Sci. 14(5), 443-448.

Kumar, R. P., 2014. Ethnomedicinal plants used for oral health care in India. Int. J. Herbal Med. 2(1), 81-87.

O'Malley, C.M., 1992. The biology of Anopheles quadrimaculatus Say. Proc. New Jersey Mosq. Control Assoc. 79, 136-144.

Premalatha, S., Elumalai, K., Jeyasankar, A., 2013. Mosquitocidal properties of Solanum trilobatum L. (Solanaceae) leaf extracts against three important human vector mosquitoes (Diptera: Culicidae). Asian Pacific J. Trop. Med. 854-858.

Ramar, G., Suman, T., Elangomathavan, R., Jeyasankar, A., 2014. Larvicidal activity of biologically synthesised silver nanoparticles against dengue vector Ae. Aegypti (Culicidae). Discovery. 9(23), 65-68.

Rutletdge, R.C., Baker, R.H., Morris, C. D., Nayar, J. K., 2005. Human malaria. EDIS, http://edis.ifas.ufl.edu/ mg103 (22 August 2015).

Tawatsin, A., Wratten, S.D., Scott, R. R., Tharara, U., Techadamrongsin, Y., 2001. Repellency of volatile oils from plants against three mosquito vectors. J. Vector Ecol. 26, 76-82.

WHO, 2005. Guide lines for laboratory and field testing of mosquito larvicides. World Health Organization Communicable Disease Control, Prevention and Eradication, WHO Pesticides Evaluation Scheme, WHO/ CDS/ WHOPES/ GCDPP/ 2005, 13.

WHO, 2011a. World Health Organization, Guidelines on the quality, safety and efficacy of dengue tetravalent vaccine (live attenuated), WHO/DRAFT, (DEN), pp.1-93.

WHO, 2011b. Lymphatic filariasis. http://www.who.int/ mediacentre /factsheets.

WHO, 2013. World Health Organization-World Malaria Report 2013-Country Profiles. Available from: http://www.who.int/malaria/publications/worldmalariarep ort2013/wmr2013countryprofiles.pdf (accessed 25th Feb. 2014).

\section{How to cite this article:}

Ramar, G., Jeyasankar, A., 2016. Phytochemical screening, larvicidal and pupicidal activity of Murraya paniculata (L.) Jack (Rutaceae) leaf extracts against three important vector mosquitoes (Diptera: Culicidae). Int. J. Curr. Res. Biosci. Plant Biol. 3(10), 150-156. doi: http://dx.doi.org/10.20546/ijcrbp.2016.310.018 